\title{
Las brujas de las Tradiciones
}

\author{
Eduardo González Viaña \\ Instituto Ricardo Palma, Lima - Perú \\ egonzalezviana@gmail.com
}

\section{Resumen:}

Búsqueda en las Tradiciones Peruanas y en los Anales de la Inquisición de Lima de información acerca de creencias, rituales mágicos, objetos de poder y concepción del mundo. Comparación de los mismos con aquellos correspondientes al presente.

Palabras clave: mundo andino, creencias, rituales, objeto de poder, concepción del mundo.

Abstract: This is a data gathering in the Peruvian Traditions and in the Anales de la Inquisición de Lima about beliefs, magical rituals, power objects and conception of the world. There will be a comparison between these and those that belong to the present.

Keywords: Andean world, beliefs, magical rituals and conception of the world 
Eduardo González Viaña, escritor peruano radicado en Estados Unidos y con nacionalidad norteamericana; catedrático emérito en Western Oregon University, Estados Unidos. Miembro de Número de la Academia Norteamericana de la Lengua Española (ANLE) así como Correspondiente de la Academia Peruana de la Lengua.

Autor de alrededor de 60 libros. Obtuvo el Premio Nacional de Fomento a la Cultura, el premio mundial de Narración en Cuento "Juan Rulfo", el Premio Norteamericano a la mejor novela en español, entre otros. El Poder Legislativo del Perú le dio la Medalla del Congreso en 2008. Es Doctor Honoris Causa de la URP. 


\section{Introducción. Las Tradiciones}

Estaba cumpliendo 13 años de edad cuando mi padre me entregó como regalo un paquete envuelto en sobrio papel kraft, atado con discretas cuerdas de bramante y vendido en una librería de Trujillo. Ese misterioso obsequio contenía el Perú.

Se trataba de un libro y estaba destinado a convertir en "peruano de verdad"-según decía mi padre- a un jovencito nacido en el siglo XX, cerca de Trujillo, en la desértica costa norte del Perú. Con él, se iba a integrar en mi vida un recuerdo cuyo ámbito geográfico abarcaría la totalidad del mapa colonial de mi país y cuyo comienzo dataría del año 1180 de la era cristiana, según Ricardo Palma, su autor.

La edición Aguilar de Tradiciones Peruanas Completas (1954) que yo recibí entonces contiene una recopilación cronológica de las "tradiciones" que el escritor publicara anteriormente. A la misma se añaden sus otras obras:

- Anales de la Inquisición de Lima

- La Segunda Inquisición

- La bohemia de mi tiempo

- Recuerdos de España

- Artículos diversos

- Parrafadas de crítica y

- Miscelánea epistolar.

En total, eran 1796 páginas en papel cebolla que yo devoraría en ese tiempo y después... durante toda mi vida. En vista de que durante mis años de adolescente, mis mejores amigos, o tal vez los únicos, eran los libros, cuando terminé el que tenía enfrente, mi conciencia abarcaba la patria y podía yo recordar qué hechos importantes habían ocurrido durante la época de alguno de los virreyes. 
Más todavía: a pesar de que para entonces no había pisado Lima podía conocerme de memoria el mapa de la capital del Perú con los nombres originales de sus calles, y sonreír recordando la razón por la que tenían apelativos tan extraños como La Rifa o El Gato,. Plateros de San Pedro, Plateros de San Agustín, Espaderos, Petateros, Guitarreros, Milagro, Quemado, Gigante, Huevo, Ya parió, etc.

\section{Rituales y creencias mágicas y religiosas en la obra de Palma}

En un libro que, como decía antes, "es el Perú" es posible hallar todo lo que uno busca. En este caso, traté de buscar rituales y creencias mágicas y religiosas existentes y persistentes en nuestro país, y claro que encontré lo que buscaba. Tanto las Tradiciones como los Anales de la Inquisición son privilegiada fuente escrita para ello y sobre todo la que abarca un mayor período de tiempo.

"La gruta de las maravillas" es el primero de los textos que aparece en esta edición y se refiere a una gruta ubicada en "el caserío de Levitaca, provincia de Chumbivilcas" (Palma. 1967, p. 7)

La leyenda que recoge Palma relata la conquista de esa región por Mayta Cápac, el cuarto inca, acontecida supuestamente en 1181 .

Asediado por los 30 mil guerreros imperiales, Huacari, el joven gobernante de esa región, eligió en vez de la humillación de la derrota, encerrarse en el palacio para morir allí de hambre al lado de sus súbditos más cercanos.

De acuerdo con la leyenda que recoge el tradicionista, "los auquis o dioses tutelares" convirtieron en gruta el palacio y en 
estalactitas al jefe y a sus vasallos que prefirieron la muerte al oprobio de la servidumbre.

El año que se usa para situar el gobierno de Mayta Cápac es muy anterior a aquel en que se suele fijar la existencia del mítico fundador del imperio, Manco Cápac. Como se puede apreciar, la cronología que se usa es algo caprichosa. Y esto ocurre tal vez por el poco interés que pone el autor en la misma o por el grado de conocimiento que se tenía entonces de nuestra historia prehispánica.

De otro lado, Palma cita de oídas y hasta parece que bautiza con nombre en castellano, la gruta de las maravillas, a las grutas de Warari que describe Antonio Raimondi situadas en Livitaca y que tienen una longitud de 78 kilómetros. El nombre de las mismas proviene del quechua waqariy, que significa llanto, como el apelativo del gobernante suicida.

Obviamente, no se puede reclamar exactitud en las referencias prehispánicas. Lo hacemos notar solamente para referir que este es el mismo tratamiento que va a dar todo lo referente a brujería y curanderismo que son el tema de este trabajo.

"Las brujas de Ica", fechada en 161 1, es una lista inacabable de personas a quienes se tuvo por practicantes de esos menesteres. Palma no hace distinción entre brujos, curanderos, practicantes de alguna religión ajena a la oficial o, incluso, astrólogos. (Ibídem, p. 266)

Comienza la relación en 1611 , precisamente, con un astrólogo cuyo nombre no es dado a conocer, pero se señala que "floreció" en Ica en esos años. El mismo es autor de algunas cartas que llevan por títulos: "Modo de conocer cuándo un año será abundante en agua” o “¿Cómo se sabrá cuando pueda declararse una epidemia?". 
Contemporáneas al autor, son Mama Justa, a quien describe como "negra repugnantísima, encubridora de robos" y rufiana, "muy diestra en preparar filtros amorosos". La sigue Manonga Lévano, cuyas vecinas aseguraban haberla visto volar.

Na Dominguita la del Socorro vivía en los tiempos de Palma y era hábil en pronosticar desventuras así como resultados de las batallas.

Don Jerónimo Illescas "sabía echar las cartas como una francesa embaucadora". Las brujas de Cachiche merecen un par de párrafos del tradicionista. Entre ellas destaca Melchorita Zugarri, cuyo laboratorio de trabajo describe. Por fin, José Cabrera, el Chicote, a quien califica como catedrático en brujería.

"El Manchay-Puito" relata los amores prohibidos de un sacerdote con una joven del Cuzco. En verdad, en vez de personajes, el narrador señala un objeto y una pieza musical como extraños y milagrosos. Una quena introducida dentro de un cántaro, en este caso, produce una melodía capaz de comunicar a la vida con la muerte (Ibídem, p. 790).

La letra que se canta está en quechua y contiene versos tan desesperados como los que aquí se muestran.

Ricardo Palma glosa dos estrofas, supuestamente traducidas del quechua, y por lo tanto libres de la obligación de la rima:

\section{Ábreme infierno, tus puertas para sepultar mi espíritu \\ en tus cavernas. \\ Aborrezco la existencia \\ sin la que era la delicia \\ iAy! de mi vida.}

Sin mi dulce compañera 
mil serpientes me devoran

las entrañas.

No es Dios bueno el Dios que manda

al corazón esas penas

iAy! del infierno.

Para referirse a algunas pociones usadas en la brujería, el tradicionista describe en "Zurrón-currichi” el agua cuyana, de la cual dice que era "un remedio infalible para hacerse amar". El relato supuestamente ocurre en Puno (Ibídem, p. 444).

La tradición "Los malditos", ocurrida en una geografía distante, Chachapoyas, sitúa la fuente Cuyana en la cumbre de un cerro muy alto. Aquella tenía dos chorros, uno de ellos inspiraba amor. El otro, aborrecimiento. Según informa el tradicionista, los jesuitas destruyeron la fuente en 1610 "y extirparon la idolatría de que era objeto” (Ibídem, p. 236).

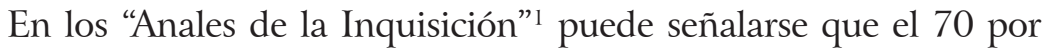
ciento de las causas corresponden a brujería y el 82 por ciento a mujeres. Los castigos son, la mayoría de las veces, de una perversidad tal que la muerte parece ser el mal menor. Condenados a padecer prisión como también así enterrados vivos, muchos no pueden soportar ese régimen y mueren, así como otros, los más felices tal vez, logran suicidarse (pp. 1205-1290).

Sin embargo, los inquisidores ordenan que se recojan los restos y que se haga con ellos una estatua que también debe ser quemada.

Examinemos algunos. Todos corresponden a los autos de fe celebrados en 1736 (pp. 1208-1221):

l En las siguientes líneas se reproduce información aparecida en la versión de Andes de la Inquisición publicada en Palma 1967. 
Micaela Zavala era una mulata limeña, de 33 años de edad, soltera y de ejercicio vendedora de jamón. Fue convicta y confesa, con auxilio del torno, de pacto con el diablo, quien la ayudó en la preparación de los brebajes y hechizos para que los hombres la amasen. Según comenta Palma.

La magia de esta infeliz fue su belleza, a la que no pudo resistir ni aún uno de los familiares del Santo Oficio, según barruntamos por cierto incidente del proceso... Abjuró de vehementi y fue sentenciada a 10 años de destierro en Pisco (p. 1240).

Igual suerte, y por los mismos presuntos delitos, corrieron María Teresa de Malavia, desterrada a Arequipa; Feliciana Fritis, desterrada a Concepción, Chile; y María Hernández, confinada en Lambayeque. A esta última, los inquisidores acusaron de usar una "mano de gloria", es decir, la mano de un ahorcado sirviendo de candelero.

Atribuíase a semejante luz el poder de inmovilizar a las personas a quienes alumbrase.

Por su parte, Sabina Rosalía de la Vega fue acusada de usar la "agujeta" y condenada a recibir azotes y a ser expulsada a Chancay. Ricardo Palma explica el uso de la misma de esta forma:

Cuando una mujer deseaba que su marido fuera impotente para con las demás, tomaba a la aguja con que había sido cocida la mortaja de un cadáver y la escondía en una pieza del vestido del pobre hombre a quien maleficiaba (p. 1241).

Esos eran los castigos menores destinados tan solo a incrementar el terror que el régimen virreinal necesitaba para sobrevivir. Veamos, sin embargo, otros casos con penas mayores: 
María Francisca Ana de Castro, natural de Toledo, en España, casada, de 47 años, judía judaizante, convicta, negativa y pertinaz...

Ana de Castro - dice Palma-pasaría hoy por una cortesana de gran tono que había vendido sus favores a subido precio a uno de los virreyes y a los más encumbrados y ricos caballeros de la nobleza colonial... (p. 1243).

Se le acusó de oír misa sin descender del carruaje. Ello significaba, para los jueces, que era judía y hechicera. Sin embargo, a pesar de haber sufrido durante tres veces el tormento, doña Ana no se confesó culpable.

Salió al auto con sambenito de dos aspas, coroza, soga al cuello y cruz verde en la mano. Luego que le fue leída su sentencia, la Inquisición la entregó a los verdugos, y sus bienes fueron confiscados.

Añade Palma que: "Luego que fue entregada al brazo secular, el general don Martín de Zamudio, alguacil mayor de Lima, la condujo al brasero en medio del aplauso popular". (p. 1244).

Según la descripción, al pasar por la Iglesia de Desamparados, la sentenciada dio muestras de arrepentimiento y rompió a llorar, pero su acompañante no quiso privar a los espectadores del desenlace que se iba a realizar en la plaza de toros.

Inflamada la hoguera y después de arrojados en ella las estatuas y huesos del jesuita Ulloa y de su paisano Vasco, devoraron las llamas el gallardo cuerpo de la desventurada doña Ana. Las cenizas fueron arrojadas al río (Ibíd.).

María de Santo Domingo, beata dominica, natural de Trujillo, de 20 años de edad, conocida con el apodo de "la dedos pegados" por tener esa imperfección física. Afirmaba que era castigadora 
de demonios, que había sacado del purgatorio tales y cuales almas, fingía revelaciones, éxtasis y visitas de la Virgen y del patriarca. Sus embustes le habían conquistado fama de santa. La sentenciaron a reclusión en un beaterio.

Doña Inés de Velasco, natural de Sevilla, de 35 años de edad. Fue juzgada por haber escrito varios cuadernos de revelaciones místicas en los que la Inquisición descubrió setenta y ocho proposiciones heréticas y malsonantes. Decía que con la Virgen y los ángeles mantenía frecuentes coloquios y que un solo jubileo sacó 5 mil almas del purgatorio.

Leonor Verdugo, mestiza, viuda y de 40 años, natural de Chuquisaca, fue acusada de fingir hechizos con hierbas y calaveras. La sentenciaron a recibir cien azotes y a tres años de encierro en un beaterio.

Ana María Pérez, mulata, natural de Cuenca, por haber fingido ser profetisa, tenido éxtasis y creerse santa desde el vientre de su madre, fue sentenciada a doscientos azotes y cinco años de reclusión.

Juan de la Rosa Urquizu, mulato, limeño, de 20 años, de profesión sastre. Lo acusaron de blasfemo y haber sostenido proposiciones heréticas. Abjuró de levi, sirvió dos años en un hospicio y se le aplicaron cien azotes.

Francisca Andrea de Benavides, de 60 años, mulata, limeña y cocinera. Hacía con las hojas de coca conjuros para que los bodegueros ganaran en su negocio y las mujeres tuvieran buena suerte. Doscientos azotes la curaron de su locura y fue a terminar su vida en Valdivia.

Inés de la Peñalillo, limeña, de 40 años y dueña de una mazamorrería. Era una mujer blanca y poseía una decente 
fortuna. Sus criadas la acusaron de hechicera y de que meneaba la mazamorra con una canilla de muerto. La infeliz dio un paseo a medio vestir y pasó a condimentar mazamorra en el presidio de Valdivia. Abjuró de levi y le fueron confiscados sus bienes.

Petronila Guevara, llamada la Cimbradora, era nacida en Lima, tenía 60 años. La acusaron de que evocaba al diablo cojuelo y daba sahumerios a las muchachas para engatusar a los hombres de que usaba la agujeta, de que enseñaba a la damiselas el uso del hilo respondón, y de que, con el auxilio de una calavera que se robó del hospital de Santa Ana, practicaba ciertas hechicerías. Fue paseada a medio vestir por las calles y aunque por su larga fecha escapó del rebenque, no por eso se libró de ir a morir en Valdivia.

María Barreto y Navarrete, zamba, natural de Guayaquil, vecina del Callao, de 36 años, cocinera y vendedora de nieve, fue acusada de hechicería, de remendar doncelleces y de encuadernadora de pecados sucios. Dicen que hacía sus conjuros mascando coca y pronunciando esta oración: "!Mama coca! i Mama querida! iLinda mía! No lo hago por vicio, sino porque me das fuerza y ventura. Yo te conjuro por el diablo de los escribanos, por el diablo de los sastres, por el diablo de las buenas noches, por los diablo de Potosí, Trujillo y por el diablo cojuelo. Te pido, traigas arrodillado a los pies de la mujer por quien te ruego al hombre que desea..." (p.1248). Tuvo la misma condena que la anterior.

Juan Alejo Romero, mestizo, natural de Cajamarca y de 80 años. Lo acusaron de haber llevado una noche a una quebrada a varias mujeres con el fin de hacerlas hechiceras.

En el lugar, colocó un crucifijo boca abajo, con un real de a dos en la espalda y estuvo en vela toda la noche en unión de ellas y del demonio. Al amanecer puso el crucifijo boca arriba con 
cinco reales sencillos en las cinco llagas: dos en los pies, dos en las manos y uno del costado.

Entonces exclamó señalando a los diablos: "vosotros sois los poderosos y el que está aquí rendido no puede ni es nada: favorece a esas mujeres para que sean amadas."

Abjuró de vehementi, salió al auto con sambenito de media aspa y concluyó sus días recluido en el noviciado de los padres jesuitas... (Ibíd.).

\section{Parafernalia de una operación de brujería}

En el texto "De cómo desbanqué a un rival", el narrador finge ser personaje de una sesión de brujería, y se vale de eso para describir la sala de trabajo de una bruja.

La María Pipí o barragana del enemigo malo nos jugó la baratija, nos hizo la brujería de las tijeras, la sortija y el cedazo, ensalmo de la piedra imán y la cebolla albarrana y, en fin, todas las habilidades que ejecuta cualquier bruja de tres al cuarto.

Luego nos pusimos a examinar el laboratorio o salita de aparato.

Había sapos y culebras en espíritu de vino, pájaros y sabandijas disecados, frascos con agua de colores, ampolleta y esqueleto; en fin, todos los cachivaches de la profesión. (p. 1439).

Además, “La lechuza, el gato y el perro empajado no podían faltar: son de reglamento, como el murciélago sobre un espejo y la lagartija entro de una olla" (Ibíd.). 


\section{Correspondencia con la tradición precolombina. Elementos prehispánicos en los rituales}

El recurso del cuy y otras operaciones prehispánicas supervivientes se muestran también en "Supersticiones de los peruanos", un texto que relata hechos contemporáneos al narrador (pp. 1430-1434).

Este es un verdadero repertorio de creencias, personajes, objetos de poder e incluso elementos de una concepción del mundo. Véase, por ejemplo:

\section{Quinua... cebo de llama}

Brujos hay que con quinua, habas, maíz, trigo o cebada, reducidos a harina y mezclados con el cebo de llama, forman una pasta con la que frotan el cuerpo del enfermo, el cual, durante la operación, cierra los ojos y reza un credo. Enseguida el brujo va destorciendo el ovillo de hilo sobre la cabeza del doliente, y lo corta en pedacitos, que luego recoge cuidadosamente, encomendándose entretanto la víctima a los santos de su devoción. Luego le rocía el rostro con aguardiente, invocando los espíritus moradores de cerros y huacas, y váse el curandero al campo, donde quema el hilo de los restos de la pasta, o los hace beber en una poción al enfermo (p. 1431).

\section{Santiago}

Los indígenas creen firmemente en los espíritus malignos. Las tempestades son producidas por un demonio denominado Santiago, que, como el santo patrón de España, anda por los aires montado en caballo blanco, el que echa chispas de fuego. A él invocan los brujos para sus maleficios. 
En oposición al Santiago del mal, reconocen un Santiago del bien, protector de sementeras y ganados, al cual representan también a caballo blandiendo un alfanje, para ahuyentar los espíritus dañinos (p. 1430).

\section{La cura del cuy}

Cuando un enfermo resiste a la eficacia de las hierbas medicinales, se apela a la ciencia de la bruja o del brujo del lugar. Constituido a la cabecera del doliente, pide una botella de aguardiente, un macito de cigarros, cuatro onzas de coca, maíz, cebada, trigo, habas y quinua, un pedazo de picho huira o grasa de techo de una llama, un ovillo de lana y un conejo vivo [se refiere al cuy]. Tomado este de los pies, fricciona con él el cuerpo del enfermo, lo pasa por el estómago, frente o pulmones, grita el animal, declara el brujo que esa es la parte afectada o enferma, que el individuo sido hechizado y que antes de comprometerse a curarlo necesita analizar por la noche a las estrellas (pp. 1430-1431).

\section{Un puñado de coca}

Otros brujos toman un puñado de coca, la esparcen sobre un pañuelo o camisa del enfermo, y después de evocar a Jesucristo y a tales o cuales santos, sopla la coca y diagnostican según la dirección que han tomado las hojitas (p. 1431).

\section{Polvo de lagartija}

Otros matan una lagartija en el mes de diciembre, la reducen a polvo; los echan en un vaso de chicha o aguardiente, y es seguro que producirá frenesí amoroso en la mujer que lo beba (Ibíd.). 


\section{El juicio de Palma}

En el texto "Supersticiones de los peruanos", el tradicionista da su juicio:

La nación fundada por Manco Cápac fue por excelencia supersticiosa. Vino la conquista, y con ella el cristianismo con su idolátrico desfile de imágenes, sus risibles milagros y su inmenso cortejo de supersticiones. Éstas cayeron sobre terreno fértil y la raza indígena aumentó con ellas el caudal propio.

Entre los legajos que forman el archivo del sabio naturalista Raimondi, y que se encuentran hoy en la biblioteca de la Sociedad Geográfica, hemos encontrado un manuscrito de 104 pliegos, en folio, sobre costumbres y preocupaciones de nuestros indígenas. El autor, en mi concepto, es el viajero peruano don Juan Gastelú (p. 1430).

Si Gastelú es la fuente, a Ricardo Palma se le debe haber recopilado y conservado esos archivos. Sin embargo, como podemos ver, su opinión es la de un liberal del siglo XIX, racional, incrédulo y, según nos revela Rubén Darío, francmasón, iniciado en la logia "Concordia Universal" del Callao.

No hace diferencia entre lo que corresponde a la tradición prehispánica y las creencias europeas impuestas por la Colonia y la Inquisición. Ni mucho menos encuentra el sincretismo resultante de esa mezcla.

Por otra parte, dada la poca importancia que Palma encuentra en estas "supersticiones", tampoco hay rigor en las fechas que establece.

Como se puede ver en las condenas mostradas en los "Anales de la Inquisición de Lima", los delitos de las personas dedicadas supuestamente a la hechicería son invenciones de los propios inquisidores y de las confesiones obtenidas por tortura. 
Después de padecer años sepultados en prisiones subterráneas, los sospechosos perdían la razón o estaban dispuestos a confesar todo lo que sus implacables jueces les ordenaran.

El texto "De cómo desbanqué a un rival" es el único en que el escritor se declara testigo, pero el laboratorio de la bruja es tan inventado como la propia bruja. No aparecen tales elementos en las operaciones mágicas operadas en el país.

La mesa de brujería es diferente, muy diferente del "laboratorio de María Pipí". Es, más bien, un altar en que se encuentran representadas las diferentes potencias del universo, las montañas, los ríos y los personajes que son capaces de cambiar el rumbo de nuestras vidas.

No se trata tan solo de una mesa de brujería actual sino de la que describen los documentos de "extirpación de idolatrías" anteriores a la implantación de la Inquisición en el Perú. En este artículo, los apéndices corresponden a dos procesos sobre ese tema tomados de los archivos del Episcopado de Lima.

Más todavía, en diversos cerámicos prehispánicos se pueden apreciar plantas de poder y rituales que han mantenido una irrompible continuidad en nuestro tiempo.

Obviamente, la vieja brujería contiene también un sincretismo y, en ella, los símbolos de la cultura autóctona y aquellos de la española se conciertan.

\section{En resumen:}

1) Las Tradiciones son un extraordinario recuento de las creencias mágicas supervivientes en el Perú colonial y en la Lima de Palma. Por su parte, los Anales de la Inquisición de Lima, aunque comentados por él, son un documento indispensable 
para conocer la naturaleza de los delitos que ese tribunal juzgaba al igual que las formas de tortura aplicadas en la investigación y el extremo sadismo de las penas decretadas.

2) Palma es un periodista, no un antropólogo. No establece diferencias entre magia y religión ni entre los elementos indígenas y los europeos existentes o sincréticos. No va hacia la razón de ser de los cultos y se queda en la superficie de los mismos. Se limita a burlarse de ellos y a cuestionarlos de modo general.

3) Su visión es la de un hombre ilustrado de su tiempo. Era liberal, racionalista, masón y estaba enfrentado a una iglesia a la que todavía se le podía acusar de los delitos que le imputó la Reforma.

4) Conoció bien el mecanismo de la Inquisición, pero no los documentos producidos por los "extirpadores de idolatrías" antes de que se implantara esta institución.

5) Algunas de sus referencias se deben sobre todo a su afán fantasioso que lo lleva a nublar la realidad o a inventarla, como su descripción del supuesto laboratorio de una bruja, lo que podría tal vez existir en la Europa de entonces o en los cuentos infantiles, pero no en el Perú.

6) Por fin, la brujería es, en nuestras tierras, supervivencia de una vieja religión, anterior a la conquista española, que no ha podido ser suplantada por completo. Es también vestigio de una ciencia de curar cuya eficacia hasta hoy es evidente.

7) Nada de todo esto lo sabríamos si no fuera por esa memoria milagrosa que nos entregaron las Tradiciones. A Ricardo Palma hay que visitarlo con la misma simpatía con que lo hizo Rubén Darío, para conservar eternamente el recuerdo 
de aquel viejecito amable, de aquel buen amigo, de aquel glorioso príncipe del ingenio.

\section{Apéndices}

Procesos de extirpación de idolatrías tomado de los archivos del Episcopado de Lima. (De los libros iHabla, Sampedro. Llama a los brujos! y Don Tuno, el señor de los cuerpos astrales, de Eduardo González Viaña.) (2009, pp. 303-321)

\section{De cómo resultó hechicería Venerar a los antepasados}

En el pueblo de San Lorenzo de Quinti, 22 de abril de 1660, el Licenciado D. Juan Sarmiento, Visitador Eclesiástico y Extirpador de Idolatrías del Arzobispado de Lima, dijo que por cuanto, luego de una requisitoria que se leyó en la iglesia de Quinti, una persona temerosa de Dios y, por descargo de su conciencia, en secreto por el riesgo de su vida, dio a su Merced un memorial en el que denunciaba a algunas personas que son hechiceras... y en el dicho memorial está escrito y asentado el nombre de Lucía Suyo Cargua...

...Por ello... se mandó comparecer ante el Visitador a Lucía Suyo Cargua, con intérprete. Y dijo que no sabe más que sobar la barriga y hacer parir a las preñadas, y dar bebedizos a los enfermos para curarlos.

Exhortada nuevamente, dijo que de siete años a esta parte ha tenido por costumbre por la fiesta de San Lorenzo, a medianoche y antes de que cante el gallo, hacer una candelada cuando está durmiendo su gente, sin que la vea persona alguna; y que, a modo de sacrificio, echa a la candela coca, mazorcas de maíz blanco, chicha y sebo de llama. 
Preguntada a quién hacía aquellos sacrificios, dijo que los hacía ante los antepasados que estaban enterrados en dicho paraje.

Preguntada si había algunos huesos en dicho paraje, dijo que no.

Preguntándole por qué hacía esos sacrificios, dijo que un abuelo suyo llamado Tiquiachari le había enseñado y recomendado hacerlos porque los difuntos también tenían necesidad de comer...

Y preguntándole que si los indios de su ayllu cantan cuando hacen sacrificios, dijo que no cantan para no ser escuchados. Y que sólo hablan en secreto con sus muertos. Y que les dicen: «Ya veis que otro tiempo fuimos los dueños, y que hoy andamos perseguidos. Ya veis que hoy es el tiempo al revés»

Y que, callados, se van a sus casas para que no los escuche persona alguna. Y que todo esto lo dicen en su lengua materna...

Archivo del Arzobispado de Lima, Legajo 2. Expediente XIV, 1660.

\section{De cómo el demonio hace el amor con las brujas y de cómo estas confiesan}

En la estancia de Santa Ana, 9 de abril, yo D. Antonio de Cáceres, habiendo traído presa a Inés Carua Chumbi, proveí este auto para tomar confesión a dicha rea y para que con toda brevedad confesase sus delitos y declarase todas las maldades que ha cometido contra la fe que recibió en el bautismo. Para lo cual hice que el alcalde trajese a la presa y la sometiese al tormento. Y que si no confesase, o pretendiera negar (sus maldades), hiciera su oficio (el verdugo). 
Dijo que se llama Inés Carua, que es viuda de Diego Guamán Chagua y natural del pueblo de los Reyes, y que le parece que tendrá cerca de 60 años.

Dijo que ha sobado a muchos enfermos con sebo de llama para sanarlos, y que éste era su único delito.

Sometida al tormento, se le preguntó que cómo había mochado ante el quircay de Chinchaycocha. Ante lo cual, dijo que había venerado a un cerro llamado Quircay. Y que lo había hecho con su marido, Diego Guamán Chagua. Que juntos ofrecieron a dicho cerro corderos vivos y muertos.

Y que cada vez que lo hacía, llevaba dos corderos: uno blanco y otro negro.

Y que, al cerro, le decían: «Apo Quircay, Cápac Quircay.» Y «tomadlas», le decían, «estas ovejas». Para que no mueran. Para que tengamos muchas.

Y que la confesante soplaba coca sobre el cerro, y le daba a comer y a beber sebo y chicha blanca.

Y que su marido difunto era un gran maestro de brujería, y que ella lo ayudaba.

Preguntada que cuántas veces ha hablado con el demonio; dijo que dos veces. Y que el demonio traía la cara cubierta con una manta, y que no sabe si traía camiseta.

Y que, muerto su marido, le pidió al Demonio que la sustentara. Y que el demonio le dio maíz, masa de harina y papas. Y que ya van a ser cuatro años que recibe esto.

Preguntada que quién cargaba con todo esto que le daba el demonio; respondió que todo esto - la masa, el maíz y las papas 
- se aparecían en su casa. Y que el demonio le decía que lo había traído a la casa para ella.

Preguntada que cuántas veces ha dormido con el demonio, dijo que, de dos veces que vino, ha dormido con ella una vez.

Preguntada por las cosas que en la cama había dicho el demonio; vamos, vamos, dijo que no se acuerda... (ilegible) ...y que el demonio la tomó. Y vuelta a requerir (con el tormento) para que diga la verdad y para que se acuerde bien, dijo que ya se acuerda bien de ello porque siempre había estado despierta y porque había sentido gran tentación del demonio.

Preguntada que si el demonio la había poseído como su marido, cuando aquél estaba vivo; respondió que de la misma manera.

Preguntada que de qué género era la semiente que le echaba este demonio; dijo que echaba como una leche blanca.

Preguntada que si era fría o era caliente; dijo que era caliente.

Preguntada que si el miembro que le metía el demonio era como el de su marido; dijo que de la misma forma. Y que todo lo que le pregunten es verdad, que es verdad, que así lo confiesa como le ha sucedido. Y que después de tomarla, se iba el demonio sin decir palabra...

Archivo del Arzobispado de Lima, Legajo 2, Expediente $\mathrm{X}$, correspondiente al año 1650. 


\section{Bibliografía}

González Viaña, E. (1970). Habla San Pedro, llama a los brujos. Barcelona: Editorial Argos Vergara.

González Viaña, E. (2009). Don Tuno, el señor de los cuerpos astrales. Lima: Universidad Alas Peruanas.

Hampe M., T. (2006). Ricardo Palma, cronista de la Inquisición. Biblioteca Virtual Miguel de Cervantes.

Mariátegui, J. C. (1928). 7 ensayos de interpretación de la realidad peruana. Lima: Biblioteca Amauta.

Palma, R. (1967). Tradiciones Peruanas completas, tercera edición Madrid: Editorial Aguilar.

Recibido el 18 de marzo del 2019 Aceptado el 19 de marzo del 2019 